\title{
Struktura i właściwości mechaniczne złącza ze stali T91 z niskostopową warstwą graniową
}

\author{
Structure and mechanical properties of T91 welded joint \\ with low-alloy root pass
}

\section{Streszczenie}

W pracy przedstawiono wyniki badań metalograficznych złącza stali T91 spawanego dwoma materiałami dodatkowymi. Ścieg przetopowy wykonany był materiałem dodatkowym o składzie chemicznym zbliżonym do stali 10H2M, ścieg wypełniający materiał o składzie stali T/P91. Badane złącze poddane było obróbce cieplnej - wyżarzaniu $760{ }^{\circ} \mathrm{C} / 2 \mathrm{~h}$. Badania nieniszczące i niszczące wykazały, że analizowane złącze spawane spełniało wymagania jakościowe na poziomie B oraz charakteryzowało się wymaganymi lub dostatecznymi właściwościami mechanicznymi. Badania strukturalne wykazały występowanie pomiędzy ściegiem graniowym a wypełniającym pojedynczej, o szerokości i długości rzędu kilku ziaren, strefy odwęglonej.

Słowa kluczowe: stal T91; niskostopowa grań; TIG

\begin{abstract}
The paper presents the results of metal science research of the T91 steel joint welded with two additional materials. The root pass was made with the additional material with its chemical composition similar to that of the $10 \mathrm{H} 2 \mathrm{M}$ steel, and the fill pass was made with the material of the chemical composition of T/P91 steel. The examined joint was subject to heat treatment annealing $760{ }^{\circ} \mathrm{C} / 2 \mathrm{~h}$. The non-destructive and the destructive tests proved that the investigated welded joint fulfilled the quality requirements at the B level and was characterised by the required or satisfactory mechanical properties. The structural tests showed the occurrence of a single decarburised zone, its width and length being of the order of several grains, between the root pass and the fill pass.
\end{abstract}

Keywords: T91 steel; low-alloy root pass; TIG

\section{Wstęp}

Rosnące wymagania wobec stopów stosowanych na wysokoobciążone instalacje energetyczne powodują, że materiały te, będące stalami i stopami na bazie niklu muszą przenosić długotrwałe oddziaływanie znacznych ciśnień przy wysokiej temperaturze. Dlatego też prowadzi się permanentne poszukiwania optymalnych składów stopów możliwie wolno degradujących się w warunkach powodujących: pełzanie, utlenianie, erozję i kawitację, nisko- i wysokotlenową korozję lub obniżające właściwości mechaniczne stopów poprzez dyfuzyjne procesy wydzieleniowe, kruche pękanie, pękanie eksploatacyjne i korozyjne. Poszukiwania te prowadzą albo do zwiększania ilości i zawartości składników stopowych w stalach (najczęściej chromu) albo do poszerzania gamy i kombinacji nowo wprowadzanych pierwiastków $[1,2]$. Pierwiastki wykorzystywane jako składniki stopowe należą coraz częściej do rzadkich i cennych, a zatem drogich. Stale o strukturze martenzytycznej stosowane w energetyce, w tym również stal typu T/P91, charakteryzują się ograniczoną spawalnością, co wymaga stosowania przed, w czasie i po spawaniu odpowiednich zabiegów bezpieczeństwa $[1,3,4]$. Konieczne staje się podgrzewanie wstępne, regulowanie ilości wprowadzanego ciepła, stosowanie specjalnych technik spawania, zapewnianie jego ciągłości po rozpoczęciu, stosowanie często złożonych-pospawalniczych obróbek cieplnych, stosowanie drogich materiałów dodatkowych (drutów i gazów osłonowych) itp. Problemy te zostały dobitnie naświetlone m.in. w pracach $[1,4,5]$ i są tym trudniejsze do przezwyciężenia, że dobór parametrów do spawania obarczony jest nieuchronnymi błędami oszacowania i ustawienia, co niekiedy uniemożliwia skuteczną kontrolę

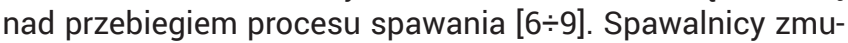
szeni są, zatem poszukiwać takich zabiegów technologicznych, które chociaż częściowo eliminowałyby niektóre trud-

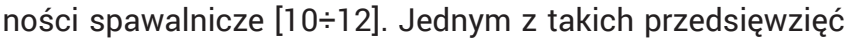
jest wykonywanie ściegu graniowego łatwospawalnym materiałem dodatkowym, niewymagającym użycia drogiego

Dr inż. Kwiryn Wojsyk; mgr inż. Agata Merda; inż. Ewelina Cieślak; dr hab. inż. Grzegorz Golański, prof. PCz - Politechnika Częstochowska.

Autor korespondencyjny/Corresponding author: kwiryn@gmail.com 
gazu osłonowego (czystego argonu) mającego wypełnić złącza rurowe od wewnątrz, a zapewniającym plastyczną, odkształcalną pierwszą warstwę spoiny [13]. Rozwiązanie to jest już implementowane podczas spawania trudnospawalnych materiałów niestosowanych w branży energetycznej. Badania tego typu rozwiązań są konieczne, jednak długotrwałe ze względu na dalekosiężne konsekwencje wprowadzenia do złącza spawanego obcego, różnego od materiałów łączonych stopu.

Celem przedstawionych w pracy wyników badań jest częściowe wypełnienie tej luki.

\section{Metodyka badań}

Badania metalograficzne zostały przeprowadzone na złączu stali T91 spawanym metodą TIG dwoma różnymi materiałami dodatkowymi. Skład chemiczny badanej stali, określony za pomocą spektrometru iskrowego SpectroLab K2 przedstawiono w tablicy I. Materiał dodatkowy stosowany do spawania stali 10H2M (Böhler W CrMo2Si ø2,4 mm) użyto do wykonania ściegu przetopowego, natomiast w celu wypełnienia rowka spawalniczego zastosowano materiał dodatkowy stosowany do spawania stali T/P91 (Böhler W CrMo91 ø2,4 mm). Skład chemiczny materiałów dodatkowych przedstawiono w tablicach II i III (zgodnie z danymi producenta) [14]. Temperatura wstępnego podgrzewania wynosiła $220^{\circ} \mathrm{C}$. Próbki spawano w pozycji PC, jako gazu osłonowego użyto argonu. Złącze spawane wykonano na rurze o średnicy zewnętrznej $76 \mathrm{~mm}$ i grubości ścianki 10,7 mm. Po spawaniu otrzymane złącze poddano obróbce cieplnej polegającej na wyżarzaniu w temperaturze $760{ }^{\circ} \mathrm{C}$ przez $2 \mathrm{~h}$ z następnym studzeniem w powietrzu. Otrzymane złącza poddano badaniom: nieniszczącym oraz badaniom niszczącym, w tym makroi mikroskopowym. Badania mikroskopowe przeprowadzono za pomocą mikroskopu świetlnego Axiovert 25 na zgładzie metalograficznym trawionym chlorkiem żelaza. Badania nieniszczące obejmowały: wizualne (VT), magnetycznoproszkowe (MT) oraz radiograficzne (RT). Badania niszczące obejmowały: statyczną próbę rozciągania, próbę zginania, próbę udarności, pomiar twardości i mikrotwardości. Próbę zginania przeprowadzono przy zginaniu: poprzecznym z rozciąganiem lica, poprzecznym z rozciąganiem grani oraz bocznym.

Próbę udarności wykonano wykorzystując próbki niestandardowe, o szerokości pomniejszonej do 7,5 mm. Pomiar twardości wykonano przy użyciu twardościomierza Future-Tech FV 700 przy obciążeniu 10 kG $(100 \mathrm{~N})$, natomiast pomiar mikrotwardości wykonano przy pomocy mikrotwardościomierza Shimadzu HMV-G20 przy zastosowaniu obciążenia 0,1 kG (1 N). Wszystkie badania właściwości mechanicznych przeprowadzono zgodnie z obowiązującymi

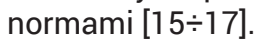

Tablica I. Skład chemiczny stali T91, \% masy

Table I. Chemical composition of T91 steel, \%mass

\begin{tabular}{|c|c|c|c|c|c|c|c|c|}
\hline C & Si & Mn & P & S & Cr & Mo & V & Nb \\
\hline 0,09 & 0,37 & 0,37 & 0,01 & 0,003 & 8,83 & 0,95 & 0,19 & 0,08 \\
\hline
\end{tabular}

Tablica II. Skład chemiczny materiału dodatkowego Böhler W CrMo2Si, $\%$ masy

Table II. Chemical composition of additional material Böhler W CrMo2Si, \% mass

\begin{tabular}{|c|c|c|c|c|c|c|c|c|}
\hline C & Si & Mn & Cr & Mo & P & AS & Sb & Sn \\
\hline 0,06 & 0,71 & 0,95 & 2,60 & 1,02 & $\leq 0,01$ & $\leq 0,01$ & $\leq 0,005$ & $\leq 0,006$ \\
\hline
\end{tabular}

Tablica III. Skład chemiczny materiału dodatkowego Böhler W CrMo91, \% masy

Table III. Chemical composition of additional material Böhler W CrMo91, \% mass

\begin{tabular}{|c|c|c|c|c|c|c|c|}
\hline $\mathbf{C}$ & $\mathbf{S i}$ & $\mathbf{M n}$ & $\mathbf{C r}$ & $\mathbf{N i}$ & $\mathbf{M o}$ & $\mathbf{V}$ & $\mathbf{N b}$ \\
\hline 0,12 & 0,33 & 0,50 & 9,03 & 0,72 & 0,91 & 0,20 & 0,055 \\
\hline
\end{tabular}

\section{Wyniki badań i ich omówienie}

\section{Badania nieniszczące, metalograficzne makro- i mikroskopowe}

Przeprowadzone badania nieniszczące nie ujawniły występowania niezgodności spawalniczych spełniających wymagania dla poziomu jakości B według normy [18].

Badanie makroskopowe ujawniło prawidłową budowę złącza i nie wykazało występowania żadnych niezgodności spawalniczych (rys.1).

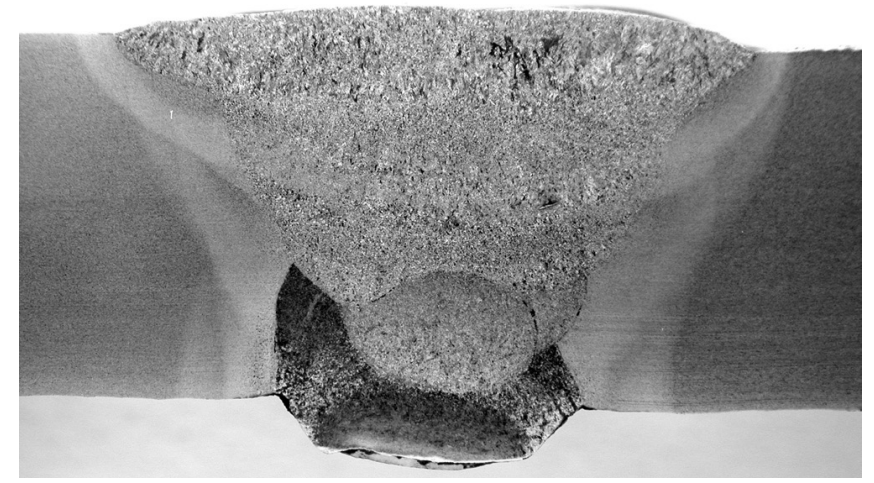

Rys. 1. Makrostruktura złącza doczołowego stali T91, pow. 4x Fig. 1. Macrostructure of butt joint of T91 steel, magn. 4x

Przeprowadzone badania mikroskopowe ujawniły w strefie wpływu ciepła (SWC) stali T91 trzy charakterystyczne obszary: gruboziarnisty w pobliżu linii wtopienia (1), normalizacji (2) i niepełnej normalizacji (3) (rys. 2). W spoinie natomiast zaobserwowano strukturę bainityczną w ściegu graniowym (rys. 3a) i martenzytyczną w ściegu wypełniającym (rys. 3b). Ponadto pomiędzy ściegiem graniowym a pierwszym ściegiem wypełniającym ujawniono pojedynczy odwęglony obszar o strukturze ferrytycznej o długości wynoszącej ok. $775 \mu \mathrm{m}$ i szerokości ok. $75 \mu \mathrm{m}$ (rys. 4a). Również w obszarze linii wtopienia zaobserwowano pojedyncze ziarna ferrytu (rys. 4b).

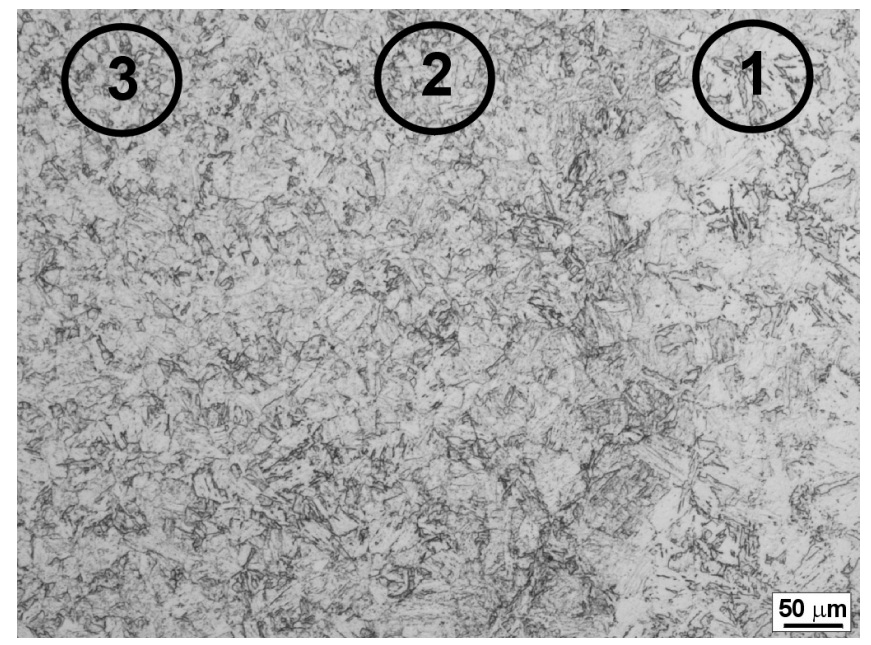

Rys. 2. Strefa wpływu ciepła stali T91, pow. x100

Fig. 2. Heat-affected zone of T91 steel, magn. x100 

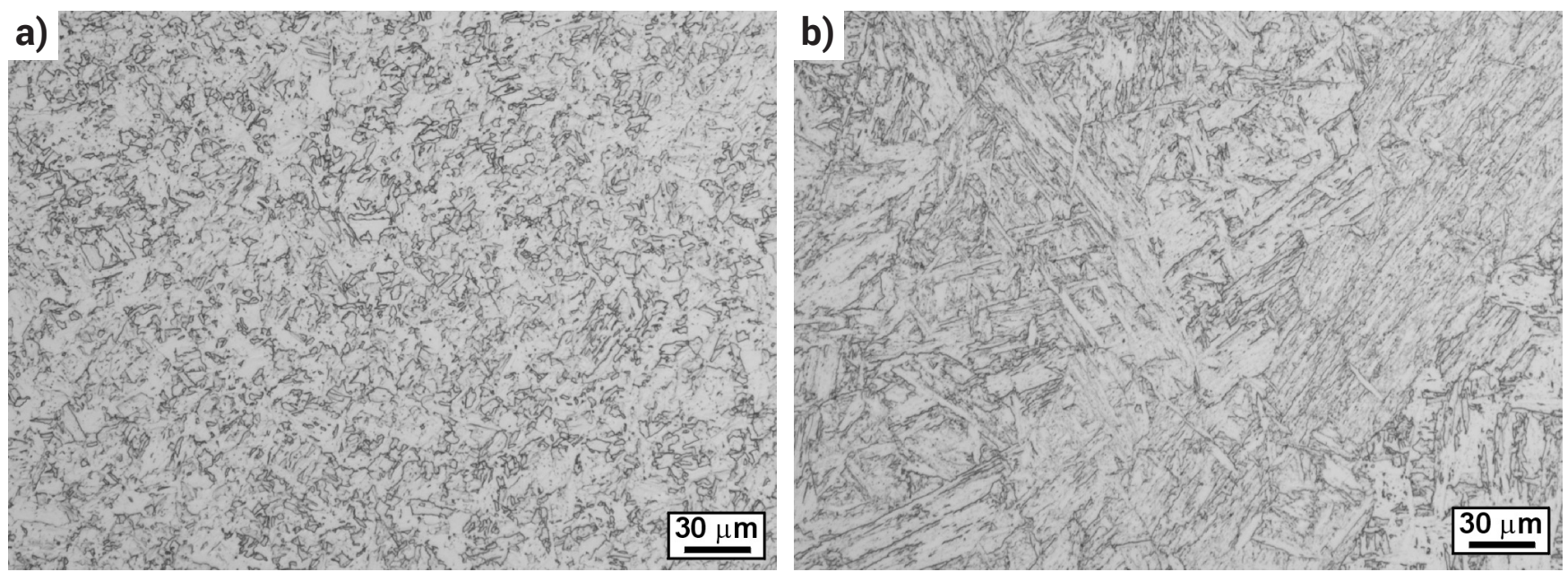

Rys. 3. Mikrostruktura spoiny: a) ścieg graniowy, pow. x200, b) ścieg wypełniający, pow. x200

Fig. 3. Weld microstructure: a) root pass; magn. $x 200$, b) fill pass, magn. $x 200$
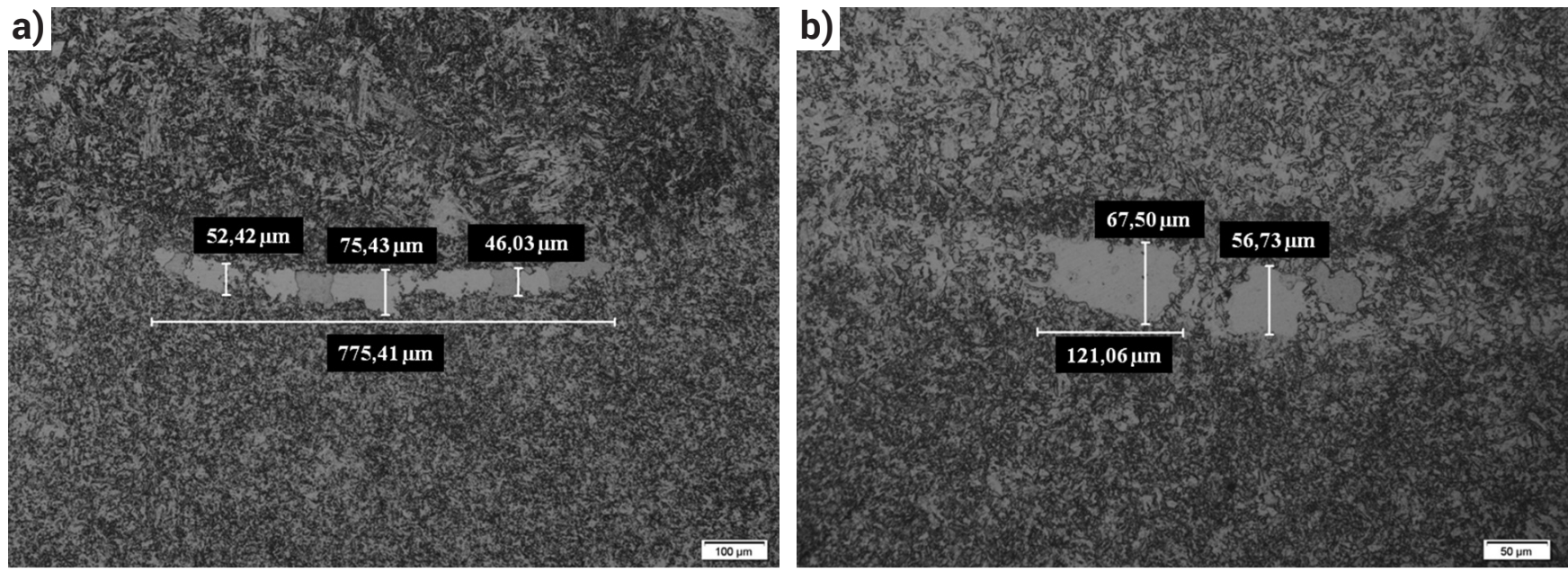

Rys. 4. Mikrostruktura strefy odwęglonej: a) pomiędzy pierwszym a drugim ściegiem, b) przy linii wtopienia Fig. 4. Decarburised zone microstructure: a) between first and second pass, b) near weld line

\section{Badania właściwości mechanicznych}

Wyniki badań właściwości mechanicznych analizowanego złącza (próby zginania i próby udarności) zestawiono w tablicy IV i V oraz na rysunku 6 (pomiary twardości). W próbie zginania pozytywny wynik uzyskuje się poprzez osiągnięcie kąta gięcia wynoszącego $180^{\circ}$ bez występujących na próbce pęknięć oraz rys.

Próby zginania złącza (tabl. IV) dla lica i grani wykazały, że pomimo nieosiągnięcia kąta $180^{\circ}$ badania należy uznać za pozytywne, gdyż próby przerwano z powodu ograniczeń konstrukcji trzpienia gnącego zamocowanego na maszynie wytrzymałościowej. Przy doginaniu próbek, rozciągana powierzchnia spoiny uległa odkształceniom w niewielkim stopniu, a na próbkach po zginaniu nie obserwowano żadnych pęknięć ani rys.

Przeprowadzona statyczna próba rozciągania wykazała, że wytrzymałość na rozciąganie analizowanego złącza wynosiła $618 \mathrm{MPa}$, a samo zerwanie miało miejsce w materiale rodzimym. Wartość ta była nieznacznie niższa od wymaganej minimalnej wartości wytrzymałości na rozciąganie

Tablica IV. Wyniki próby zginania

Table IV. Results of bending test

\begin{tabular}{|c|c|c|c|}
\hline $\begin{array}{c}\mathbf{N r} \\
\text { próbki }\end{array}$ & $\begin{array}{c}\text { Wymiary próbki } \\
{[\mathrm{mm}]}\end{array}$ & Rodzaj zginania & Kąt gięcia \\
\hline 1 & $10,0 \times 11,3$ & zginanie boczne & $146^{\circ}$ \\
\hline 2 & $10,0 \times 10,9$ & z rozciąganiem lica & $139^{\circ}$ \\
\hline 3 & $9,9 \times 10,9$ & z rozciąganiem grani & $144^{\circ}$ \\
\hline
\end{tabular}

dla stali T91 wynoszącej $630 \mathrm{MPa}$, zgodnie z wymaganiami normatywnymi [19]. Zerwanie w materiale rodzimym stali T91 wskazuje na wyższe od materiału rodzimego właściwości spoiny i potwierdza prawidłową budowę złącza spawanego. Próbę udarności przeprowadzono dla próbek z naciętym karbem w: spoinie, brzegu pierwszego ściegu i SWC. Jako kryterium akceptacji ciągliwości złącza przyjęto wartość udarności dla materiału rodzimego stali T91 wynoszącą $35 \mathrm{~J} / \mathrm{cm}^{2}$.

Tablica V. Wyniki próby udarności złącza spawanego Table V. Results of impact energy test of welded joint

\begin{tabular}{|c|c|c|c|}
\hline $\begin{array}{l}\text { Usytuowanie } \\
\text { karbu }\end{array}$ & $\begin{array}{c}\mathrm{KCV} 300 / 7,5 \\
{\left[\mathrm{~J} / \mathrm{cm}^{2}\right]}\end{array}$ & $\begin{array}{c}\text { Wartość śred- } \\
\text { nia udarności } \\
\mathrm{KCV} 300 / 7,5 \\
{\left[\mathrm{~J} / \mathrm{cm}^{2}\right]}\end{array}$ & $\begin{array}{c}\text { Odchylenie } \\
\text { standardowe }\end{array}$ \\
\hline \multirow{3}{*}{ Spoina } & 222 & \multirow{3}{*}{193} & \multirow{3}{*}{94} \\
\hline & 250 & & \\
\hline & 76 & & \\
\hline \multirow{3}{*}{$\begin{array}{l}\text { Brzeg pierw- } \\
\text { szego ściegu }\end{array}$} & 253 & \multirow{3}{*}{217} & \multirow{3}{*}{40} \\
\hline & 208 & & \\
\hline & 173 & & \\
\hline \multirow{3}{*}{ SWC } & 272 & \multirow{3}{*}{276} & \multirow{3}{*}{8} \\
\hline & 272 & & \\
\hline & 285 & & \\
\hline
\end{tabular}


Najniższa wartość udarności występowała w spoinie (tabl. V), gdzie na przełomie obserwowano przełom kruchy lub mieszany. Najwyższą wartość udarności uzyskano dla materiału z naciętym karbem w SWC, gdzie zaobserwowano ciągliwy mechanizm pękania. Uzyskane wartości udarności w złączu niezależnie od miejsca nacięcia karbu były wyższe od przyjętego kryterium.

Rozkład twardości na przekroju złącza spawanego wykonano na zgładzie metalograficznym. Schemat z zaznaczonymi miejscami pomiarów twardości w poszczególnych obszarach złącza przedstawiono na rysunku 5, natomiast rozkład twardości zobrazowano na rysunku 6.

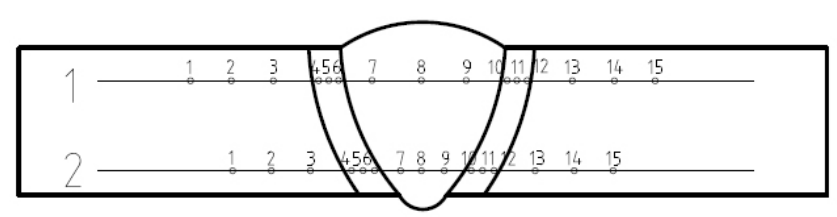

Rys. 5. Rozmieszczenie punktów pomiaru twardości

Fig. 5. Distribution of hardness measurement points

\section{Rozkład twardości}

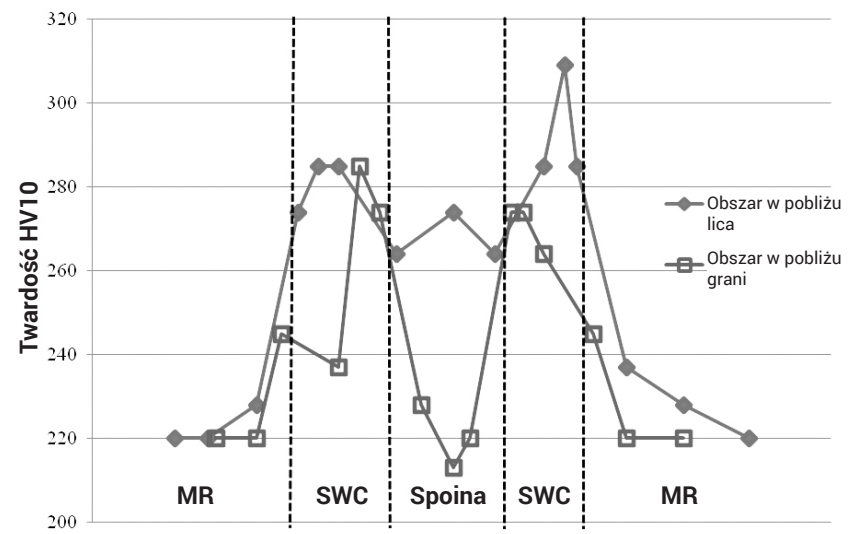

Rys. 6. Rozkład twardości na przekroju badanego złącza spawanego Fig. 6. Hardness distribution in the cross-section of the examined welded joint

Przeprowadzone pomiary wykazały, że najwyższą twardość złącze osiągnęło w SWC stali T91. Najniższą wartość twardości na przekroju złącza odnotowano w spoinie od strony grani, co wynika z zastosowanego materiału dodatkowego i bainitycznej struktury (rys. 3a). Uzyskana twardość na przekroju analizowanego złącza była niższa od wartości granicznej wynoszącej $350 \mathrm{HV}$, co stanowiło informację o braku skłonności złącza do pękania zimnego.
Ze względu na występowanie pojedynczego obszaru odwęglonego w badanym złączu przeprowadzono dodatkowo pomiar mikrotwardości. Rozmieszczenie punktów pomiarowych mikrotwardości przedstawiono na rysunku 7. Przeprowadzony pomiar wykazał obniżenie mikrotwardości badanej strefy odwęglonej w stosunku do spoiny badanego złącza (rys. 8). Różnica ta wynosiła od ok. 70 do ok. 100 HV0,1 w stosunku do mikrotwardości ściegu przetopowego czy wypełniającego.

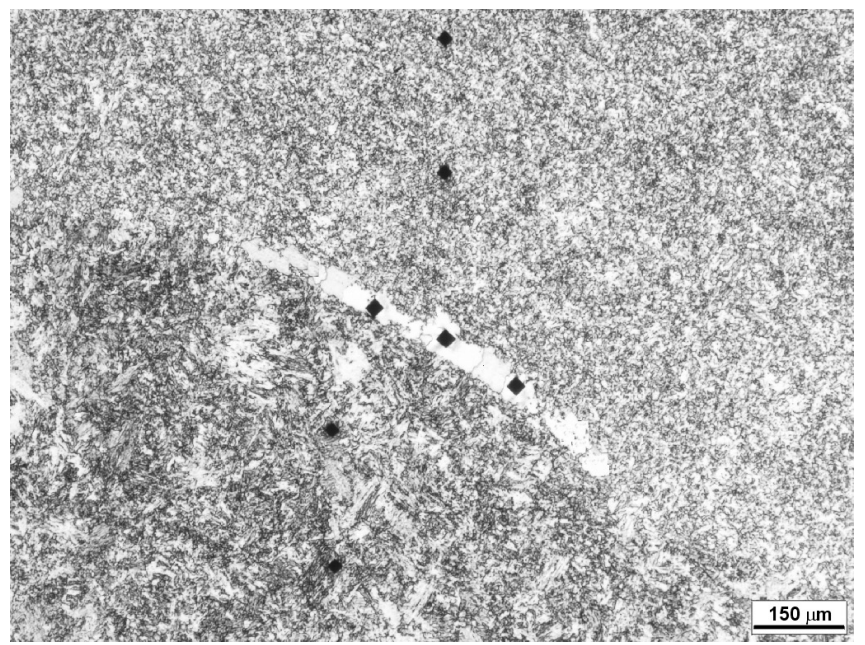

Rys. 7. Rozmieszczenie punktów pomiarowych w obszarze strefy odwęglonej, pow. x50

Fig. 7. Distribution of hardness points in the decarburised zone, magn. x50

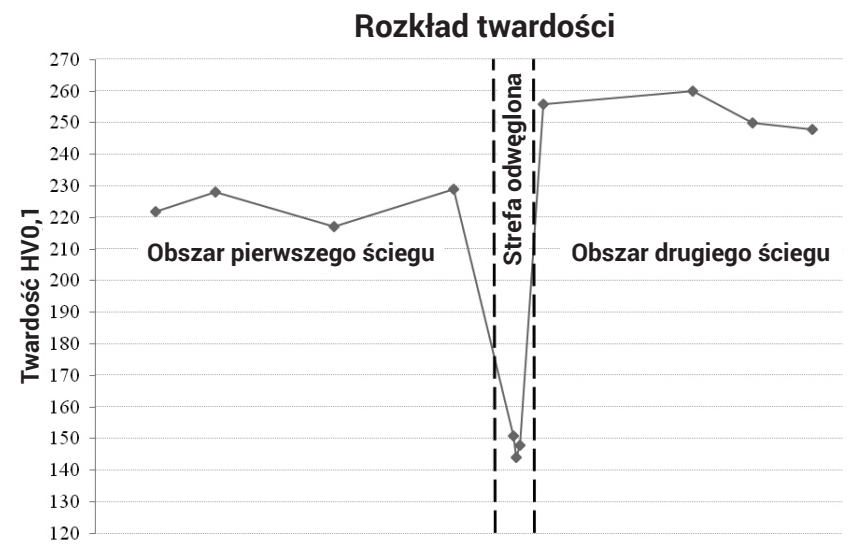

Rys. 8. Rozkład mikrotwardości w obszarze strefy odwęglonej

Fig. 8. Microhardness distribution of the decarburised zone

\section{Podsumowanie}

Badaniu poddano złącze stali T91 spawane metodą TIG dwoma materiałami dodatkowymi: ścieg graniowy - materiał o składzie zbliżonym do stali 10H2M, ścieg wypełniający - materiał o składzie stali T91. Przeprowadzone badania złącza wykazały, że:

- spoina spełnia wymagania jakościowe na poziomie B,

- badania strukturalne wykazały występowanie pomiędzy ściegiem graniowym a wypełniającym pojedynczej, niewielkiej strefy odwęglonej charakteryzującej się obniżonymi właściwościami (mikrotwardością),

- badane złącza charakteryzowały się dostateczną plastycznością, wymaganą udarnością oraz twardością niższą od wartości $350 \mathrm{HV}$,

- uzyskana wartość wytrzymałości na rozciąganie i zerwanie w materiale rodzimym stali T91 świadczy o wyższych właściwościach spoiny i SWC w stosunku do materiału rodzimego.

Kompleksowa weryfikacja przydatności złącza do pracy w instalacjach energetycznych wymaga przeprowadzenia próby pełzania oraz długotrwałego wyżarzania w temperaturze zbliżonej do przewidywanej temperatury pracy. 


\section{Literatura}

[1] Brózda J.: Stale żarowytrzymałe nowej generacji, ich spawalność i własności złączy spawanych. Cel stosowania stali żarowytrzymałych nowej generacji, ich charakterystyka i wynikające korzyści. Biuletyn Instytutu Spawalnictwa nr 1, s. 41-49, 2004.

[2] Łomozik M., Hernas A., Zeman M.: Effect of welding thermal cycles on the structure and properties of simulated heat-affected zone areas in $\mathrm{X} 10 \mathrm{Cr}$ MoVNb9-1 (T91) steel at a state after 100,000 h of operation, Mater. Sc. Eng. 637A, pp. 82-88, 2015.

[3] Łomozik M., Zeman M., Jachym R.: Cracking of welded joints made of steel X10CrMoVNb9-1 (T91) - case study, Kovove Mater., (50), s. 285-294, 2012.

[4] Brózda J.: Własności złączy ze stali P91 spawanych różnymi gatunkami spoiw, Biuletyn Instytutu Spawalnictwa nr 6, pp. 34-38, 2000.

[5] Adamiec J.: Pękanie spawanych ścian szczelnych podczas eksploatacji, Przegląd Spawalnictwa, nr 4, s. 34-38, 2018.

[6] Kudła K., Wojsyk K.: Ocena ilości ciepła wprowadzonego podczas procesów spawania łukowego, Biuletyn Instytutu Spawalnictwa nr 5, s. 121-127, 2010.

[7] Kudła K., Wojsyk K.: Obliczeniowa energia liniowa, a ilość ciepła wprowadzonego podczas spawania, Przegląd Spawalnictwa nr 12, s. 21-25, 2010.

[8] Kudła K., Wojsyk K.: Czy sposób doprowadzania ciepła ma wypływ na geometrię spoin?, Biuletyn Instytutu Spawalnictwa nr 5, s. 140-144, 2012.

[9] Wojsyk K., Macherzyński M.: Określanie energii liniowej spawania metodą pomiaru pól poprzecznych spoin, Biuletyn Instytutu Spawalnictwa nr 5, s. 75-79, 2016.

[10] Kudła K., Wojsyk K.: Possibilities of constructing safe and cort - effective shields for -heat exchangers, Polish Journal of Environmental Studies. Vol. 22 (6A) pp. 26-29, 2013.
[11] Michalczyk J., Wojsyk K.: Bezpieczne i ekonomiczne konstruowanie ekranów wymienników ciepła ze stali i innych stopów o ograniczonej spawalności, Przegląd Spawalnictwa nr 5, s. 37-42, 2014.

[12] Sorentino S.: Welding technologies for ultra-supercritical power plant materials, Materials for Ultra-Supercritical and Advanced Ultra-Supercritical Power Plants, pp. 274-316, 2017.

[13] Pawełczyk W., Wojsyk K.: Możliwości i ograniczenia spawania rurowych złączy różnoimiennych spoinami o odmiennej grani, Przegląd Spawalnictwa nr 4, s. 57-62, 2016.

[14] High Temperature and Creep-resistant Filler Metals - BÖHLER

[15] PN-EN ISO 6507-1:2018-05: Metale - Pomiar twardości sposobem Vickersa - Część 1: Metoda badania.

[16] PN-EN ISO 148-1:2017-02: Metale - Próba udarności sposobem Charpy'ego - Część 1: Metoda badania.

[17] PN-EN ISO 5173:2010: Badania niszczące spoin w materiałach metalowych - Badanie na zginanie.

[18] PN-EN ISO 5817:2014 Spawanie - Złącza spawane ze stali, niklu, tytanu i ich stopów (z wyjątkiem spawanych wiązką) - Poziomy jakości według niezgodności spawalniczych

[19] PN-EN 10216-2: Rury stalowe bez szwu do zastosowań ciśnieniowych - Warunki techniczne dostawy - Część 2: Rury ze stali niestopowych i stopowych z określonymi własnościami w temperaturze podwyższonej. 